\title{
Craniofacial abnormalities in goldenhar syndrome: a case report with review of the literature
}

\section{Ramesh Kumaresan', Balamanikanda Srinivasan', Mohan Narayanan², Navaneetha Cugati ${ }^{3}$, Priyadarshini Karthikeyan ${ }^{4}$}

${ }^{1}$ Departments of Oral and Maxillofacial Surgery, Faculty of Dentistry, AIMST University, 08100 Bedong, Kedah Darul Aman, Malaysia. ${ }^{2}$ Department of Oral Medicine and Radiology, Vinayaka Mission's Shankaracharyar Dental College, Salem 636308, Tamil Nadu, India. ${ }^{3}$ Department of Pedodontic and Preventive Dentistry, Faculty of Dentistry, AIMST University, 08100 Bedong, Kedah Darul Aman, Malaysia. ${ }^{4}$ Department of Oral Medicine and Radiology, Shree Balaji Dental College, Chennai 600100, Tamil Nadu, India.

Address for correspondence: Dr. Ramesh Kumaresan, Department of Oral and Maxillofacial Surgery, Faculty of Dentistry, AIMST University, 08100 Bedong, Kedah Darul Aman, Malaysia. E-mail: rame1264@gmail.com

\begin{abstract}
Goldenhar syndrome (oculo-auriculo-vertebral spectrum) is a rare congenital anomaly of unclear etiology and characterized by craniofacial anomalies such as hemifacial microsomia, auricular, ocular and vertebral anomalies. In many cases, this syndrome goes unnoticed due to a lack of knowledge about its features and because of its associated wide range of overlapping anomalies. Herewith, we present a case of Goldenhar syndrome in a 21-year-old male, who presented all the classical signs of this rare condition. This article also summarizes the characteristic features of patients with Goldenhar syndrome.
\end{abstract}

Key words:

Congenital abnormalities, eye abnormalities, Goldenhar syndrome, oculo-auriculo-vertebral spectrum

\section{INTRODUCTION}

Goldenhar syndrome is a rare developmental anomaly involving structures derived from first and second branchial arches of the first pharyngeal pouch, the first branchial cleft, and the primordial stapedial artery of the temporal bone. ${ }^{[1,2]}$ Goldenhar syndrome and its variants, also referred to as Goldenhar anomalad, occupy a central position in the broad spectrum of overlapping anomalies related to the eyes, ears, face and vertebral column. ${ }^{[2]}$

In many cases, this syndrome goes unnoticed secondary to its associated wide range of overlapping anomalies. $^{[3]}$ This work reports a case of Goldenhar syndrome in a 21-year-old male, who presented all the classical sign of this rare condition. The patient agreed to publish his facial pictures and signed the consent form.

\begin{tabular}{|l|l|}
\hline \multicolumn{2}{|c|}{ Access this article online } \\
\hline Quick Response Code: & Website: \\
\hline & www.parjournal.net \\
\cline { 2 - 2 } & \\
\hline & \\
\hline
\end{tabular}

\section{CASE REPORT}

The patient is a 21-year-old male who reported to the Department of Oral Medicine and Radiology, with complaints of an unaesthetic facial and dental appearance. He was the product of his mother's second pregnancy, the first terminated by spontaneous abortion at about 2 months of gestation. Prenatal history revealed that the mother suffered from frequent severe vaginal bleeding during the first trimester of her pregnancy. He was born at full term after a normal delivery with a bilateral complete cleft lip/palate and a congenital epibulbar dermoid of the right eye. His parents were nonconsanguineous, and there was no relevant family history.

At 6 months of age, he underwent surgery for cleft lip repair, and cleft palate closure was performed at 18 months of age. He sustained multiple episodes of epilepsy until the age of 6 years at which time he was diagnosed with hydrocephalus, and a ventriculoperitoneal shunt was placed. At the age 8 , he underwent a minor surgical procedure for excision of preauricular tags on the left side of his face.

Physical examination at the age of 21 years was remarkable for developmental and mental disability 
with a slow gait. On extra-oral examination, the patient demonstrated gross facial asymmetry, and severe retrusion of the midface and mandible. Well-demarcated postcleft deformities were noted. There was marked deviation of the nasal septum toward the left side of the face, and the patient was noted to be an obligate mouth breather [Figures 1 and 2]. The scar on the left cheek region indicated a previously excised preauricular tag, and soft tissue is deformity involving the left ear was present [Figure 2].

Intraoral examination revealed a V-shaped, constricted maxillary arch and a scar secondary to his repaired cleft palate. A large nasoalveolar fistula was noted in the line of the cleft palate repair, resulting in the hypernasality on pronation. The patient maintained poor oral hygiene with heavy calculus deposition and the generalized gingivitis. Dental examination revealed an anteriorly protruding mandible and loss of teeth 11, 21 and 22 [Figure 3]. The tongue was enlarged with hypertrophied bilateral adenoids.

Ophthalmologic examination revealed a yellowish white sub-conjunctival mass measuring $3 \mathrm{~mm} \times 3 \mathrm{~mm}$, located at the nasal limbus at the 9 O'clock position in the left eye.

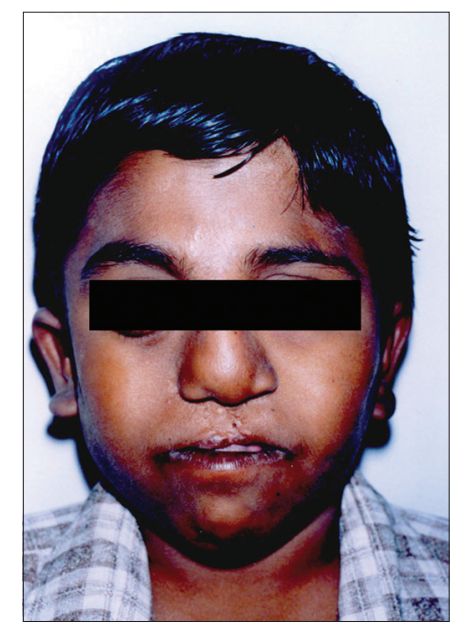

Figure 1: Extroral photograph; frontal view showing facial asymmetry and cleft lip surgery secondary deformity

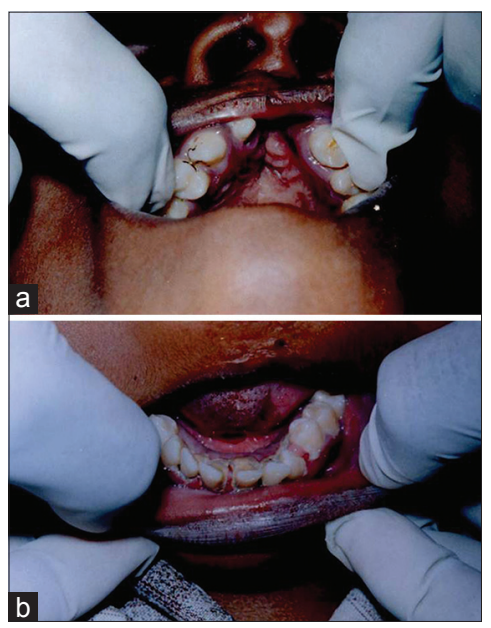

Figure 3: Introral view. (a) Maxillary arch showing constricted maxillary arch and nasoalveolar fistulae; (b) mandibular arch showing protrusive mandibular anteriors and inflamed gingiva
The mass, which contained dermal elements, was found to encroach upon the cornea by $1.5 \mathrm{~mm}$. These findings are suggestive of a limbal dermoid [Figure 4a]. The lateral canthus of the left eye additionally showed a soft, mobile whitish mass growing in the bulbar area, which was clinically suggestive of a dermolipoma. Examination of the right eye revealed a reddish sub-conjunctival mass around the inferior half of the cornea, almost filling the palpebral fissure from medial canthus to the lateral canthus, suggestive of a bleeding epibulbar dermoid [Figure 4b].

Lateral cephalogram showed a concave skeletal profile and high mandibular angle with clockwise rotation indicating increased vertical growth. The shadow of the ventricular shunt was also evident along the cervical region [Figure 5]. Water's view X-ray revealed left malar hypoplasia [Figure 6]. Maxillary occlusal radiograph demonstrated a cleft alveolus and palate with impaction of teeth 12 and 23 .

Based on the classical signs and associated abnormalities we arrived at a clinical diagnosis of Goldenhar syndrome. The patient was informed about the requirement for a multidisciplinary treatment approach due to the wide range of anomalies. Thorough oral prophylaxis reinforced

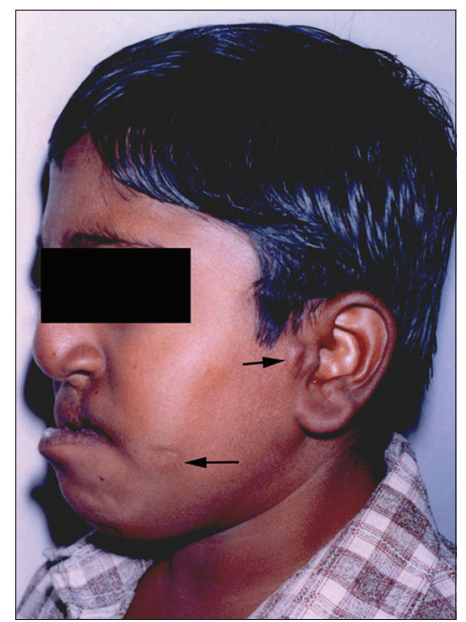

Figure 2: Extra-oral photograph; left lateral view showing preauricular tag and midface retrusion

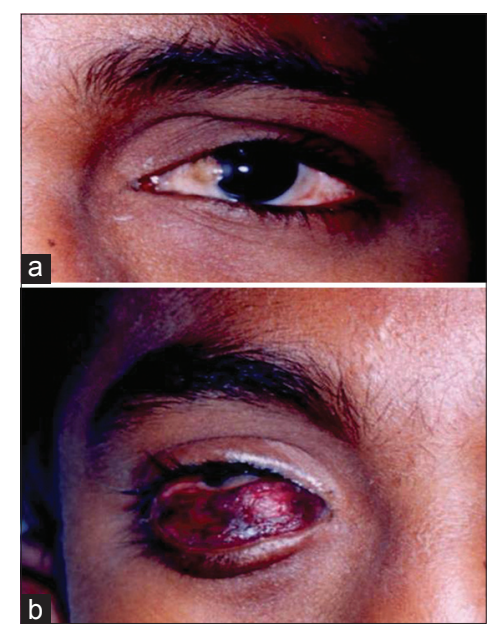

Figure 4: (a) Left eye showing limbal dermoid in the nasal aspect and dermo-lipoma in the temporal aspect; (b) right eye showing extensive epibulbar dermoid 


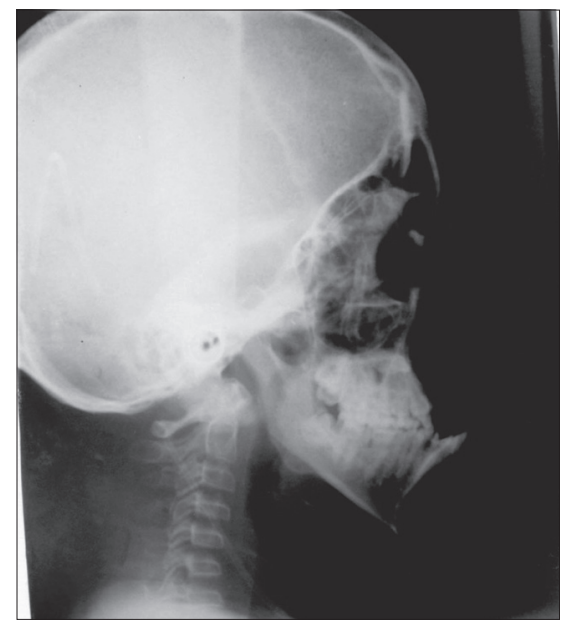

Figure 5: Lateral cephalogram demonstrating a high mandibular angle with a clockwise rotation, midface retrusion and the shadow of ventricular stunt

with education should improve the oral hygiene status of the patient. A series of surgical treatments including alveolar bone grafting, Lefort I osteotomy and maxillary advancement, followed by rhinoplasty and pharyngoplasty was suggested. The need for extensive orthodontic intervention, speech therapy and an additional ophthalmic intervention were also emphasized.

\section{DISCUSSION}

Goldenhar syndrome is a rare congenital defect characterized by a heterogeneous constellation of malformations classically involving the face, eyes and ears. ${ }^{[4]}$ It was first recorded by the German Physician Carl Ferdinand Von Arltin in 1845, but was not recognized as a syndrome until 1952 when Dr. Maurice Goldenhar described this condition as a disease that presents with a combination of several anomalies including dermal epibulbar tumors, preauricular appendages and mandibular hypoplasia. ${ }^{[3,5-7]}$ In 1963, Gorlin et al. ${ }^{[8]}$ named this syndrome oculo-auriculo-vertebral syndrome due to the presence of additional vertebral anomalies. Hence, it was also known as Goldenhar-Gorlin syndrome. ${ }^{[9]}$

The clinical manifestations of Goldenhar syndrome closely resemble those of hemifacial microsomia and hence Smith ${ }^{[10]}$ used the term facio-auriculo-vertebral anomaly to include both Goldenhar syndrome and hemifacial microsomia. Within the medical literature, the term oculo-auriculo-vertebral spectrum is often used synonymously with Goldenhar syndrome and hemifacial microsomia. However, due to the complexity and varying severity and expression of the oculo-auriculo-vertebral spectrum, some researchers suggest that the hemifacial microsomia and Goldenhar syndrome actually represent different aspects of severity within the oculo-auriculo-vertebral spectrum. ${ }^{[11]}$ According to the medical literature, when malformations primarily involve the jaw, mouth, and ears and in most cases, affect one side of the body, the disorder is often referred to as hemifacial microsomia. If abnormalities of the vertebra and/or the eyes are also present, the disorder is often

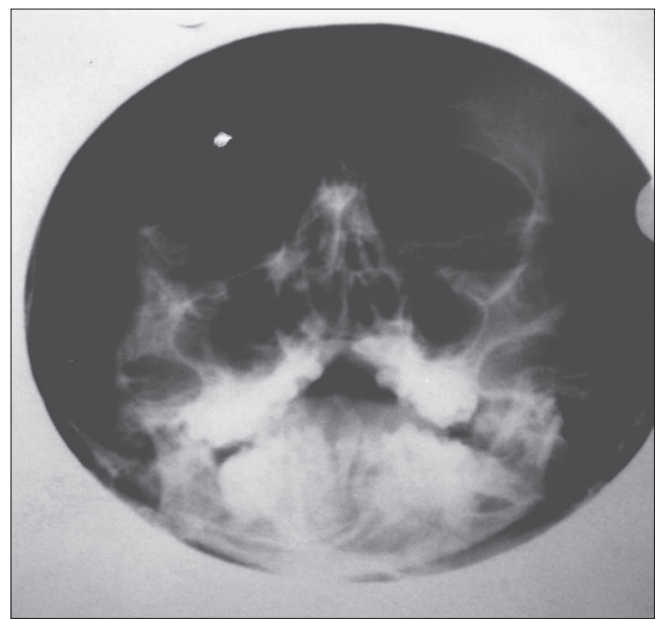

Figure 6: Water's view X-ray revealing malar hypoplasia on the left side of the face

called Goldenhar syndrome. Our patient presented with malformations involving mouth, jaws, ears and also eyes and therefore we arrived at the diagnosis of Goldenhar syndrome.

Since the description of Goldenhar and Gorlin, the variety and variability of anomalies associated with Goldenhar syndrome have been increasingly appreciated, although few authors have reported diverse ocular, skeletal, cardiac and visceral defects. ${ }^{[7]}$ In the early 1990's, this condition was better understood and it was agreed that, this syndrome may exhibit a wide range of anomalies that includes eye anomalies, ${ }^{[7]}$ disturbance of the central nervous system, cleft lip/cleft palate, ${ }^{[7]}$ facial asymmetry, developmental dental disturbances, ${ }^{[12]}$ skeletal anomalies, ${ }^{[7]}$ mental retardation, ${ }^{[4,11,13]}$ vertebral ${ }^{[14-16]}$ and congenital heart anomalies, ${ }^{[17-20]}$ growth abnormalities, ${ }^{[21]}$ pulmonary abnormalities, ${ }^{[15]}$ and labyrinthine, tracheoesophageal, ${ }^{[15]}$ renal $^{[15,16,22]}$ and genitourinary abnormalities [Table 1]. ${ }^{[17,20]}$

Its estimated prevalence is $1-9 / 100,000,,^{[13]}$ with an incidence of 1 in $25,000-45,000$ births, ${ }^{[28]}$ with a male to female ratio of $3: 2 .{ }^{[4]}$ The study of this condition is still controversial because the symptoms and the physical features vary greatly in range and severity from case to case. The characteristic combination of external ear anomalies and ipsilateral facial underdevelopment is the hallmark of this syndrome. In most of the reported cases, such malformations affect one side of the body; nevertheless, in $10-50 \%{ }^{[4,16]}$ of affected individuals, both sides of the body were involved with one side, with the right side typically more affected than the left. ${ }^{[4]}$ In our patient, both sides had virtually equal involvement of the anomaly; while he had left hemifacial hypoplasia and a notable epidermoid cyst with preauricular appendages, he also presented with an extensive epidermoid cyst of the right eye and bilateral cleft lip/palate.

The disease is seen sporadically, and its etiology is unclear. Two patho-physiologic mechanisms have been proposed for Goldenhar syndrome, reduced blood flow and focal hemorrhage in the developmental region of the first and second branchial arches occurring around 30-45 days of pregnancy, in the blastogenesis period (Poswillo's 
Table 1: Reported clinical findings in oculo-auriculo-vertebral spectrum patients and their frequencies

\begin{tabular}{|c|c|}
\hline Clinical features & Frequency $(\%)$ \\
\hline Facial abnormalities ${ }^{[4,20]}$ & 76 \\
\hline Unilateral[20,23] & $70-85$ \\
\hline Bilatera[ ${ }^{[4,16]}$ & $10-50$ \\
\hline Facial asymmetry ${ }^{[15,24,25]}$ & $65-85$ \\
\hline Unilateral facial hypoplasia ${ }^{[3,4,9,11,16]}$ & 83 \\
\hline $\begin{array}{l}\text { Hypoplasia of mandible/condyle/maxillary/malar } \\
\text { bone } \text { e }^{[7,15,23]}\end{array}$ & $50-64$ \\
\hline Cleft lip/palate $\mathrm{e}^{[4,7,9,15,16,24,25]}$ & $5-56$ \\
\hline Lateral facial cleft ${ }^{[16]}$ & $29-40$ \\
\hline \multicolumn{2}{|l|}{ Lateral cleft like extension of corner of the mouth ${ }^{[2]}$} \\
\hline \multicolumn{2}{|l|}{ Macrostomia $^{[7,12,24]}$} \\
\hline \multicolumn{2}{|l|}{ High arched palate ${ }^{[7,9]}$} \\
\hline \multicolumn{2}{|l|}{ Gingival hypertrophy ${ }^{[12]}$} \\
\hline \multicolumn{2}{|l|}{$\begin{array}{l}\text { Delayed tooth development/misaligned/ } \\
\text { supernumerary teeth }{ }^{[4,12]}\end{array}$} \\
\hline \multicolumn{2}{|l|}{ Enamel and dentin malformations ${ }^{[12]}$} \\
\hline \multicolumn{2}{|l|}{ Hypoplastic/bifid tongue $e^{[4,7,24]}$} \\
\hline \multicolumn{2}{|l|}{ Agenesis of coronid process/palatine bane ${ }^{[7]}$} \\
\hline \multicolumn{2}{|l|}{ Deviated nasal septum/choanal atresia ${ }^{[4,9]}$} \\
\hline \multicolumn{2}{|l|}{ Facial muscle hypoplasia ${ }^{[12]}$} \\
\hline \multicolumn{2}{|l|}{ Hypoplasia/aplasia of parotid glan ${ }^{[12]}$} \\
\hline \multicolumn{2}{|l|}{$\begin{array}{l}\text { Congenital salivary fistulae of accessory } \\
\text { salivary glands }{ }^{[2]}\end{array}$} \\
\hline \multicolumn{2}{|l|}{ Upslanting palpebral fissure/telecanthus } \\
\hline Ocular abnormalities ${ }^{[16,25]}$ & $25-94$ \\
\hline Epibulbar/ocular dermoid ${ }^{[14,15,25]}$ & $33.3-78$ \\
\hline Unilateral[ ${ }^{[14]}$ & 53 \\
\hline Limbal dermoid/lipodermoid ${ }^{[14,15]}$ & $47-53$ \\
\hline Unilateral & 28 \\
\hline Bilateral & 19 \\
\hline $\begin{array}{l}\text { Coloboma of upper eyelid/iris/choroidea/ } \\
\text { retina }{ }^{[14,15,24]}\end{array}$ & $24-60$ \\
\hline Bilateral ${ }^{[14]}$ & 3 \\
\hline Anopthalmos/micropthalmos ${ }^{[15,16,24,25]}$ & $10-53$ \\
\hline \multicolumn{2}{|l|}{ Strabismus/nystagmus ${ }^{[4,24]}$} \\
\hline \multicolumn{2}{|l|}{ Duane retraction syndrome ${ }^{[14,24]}$} \\
\hline \multicolumn{2}{|l|}{ Decreased corneal sensation ${ }^{[4,14,16]}$} \\
\hline \multicolumn{2}{|l|}{ Cataract and iris abnormalities ${ }^{[4,15,16]}$} \\
\hline \multicolumn{2}{|l|}{ Neuroparalytic keratitis } \\
\hline \multicolumn{2}{|l|}{ Dacryostenosis ${ }^{[24]}$} \\
\hline \multicolumn{2}{|l|}{ Proptosis ${ }^{[16]}$} \\
\hline Auricular abnormalities ${ }^{[20,23,25,26]}$ & $82-100$ \\
\hline External ear ${ }^{[20,26]}$ & $82-100$ \\
\hline Preauricular appendages and pits ${ }^{[19,25,26]}$ & $53-90$ \\
\hline Bilateral ${ }^{[14]}$ & 30 \\
\hline \multicolumn{2}{|l|}{ Ear abnormalities } \\
\hline Microtia ${ }^{[25,26]}$ & $50-100$ \\
\hline Bilateral[26] & $18-50$ \\
\hline Anotia $^{[25]}$ & 16.60 \\
\hline Atresia of outer ear canal & \\
\hline Stenosis of outer ear canal & \\
\hline Middle ear ${ }^{[18,26]}$ & $67-75$ \\
\hline Incomplete development of the tympanic cavity & \\
\hline Opacified middle ear & \\
\hline Agenesis of the middle ear & \\
\hline Hypoplasic/agenesis of the tympanic cleft & \\
\hline Hypoplastic/displaced ossicular chain & \\
\hline Widened or decreased tympanic cavity & \\
\hline
\end{tabular}

Table 1: Contd...

Clinical features

Frequency (\%)

Absence of the tympanic tensor muscle

Inner ear ${ }^{[18,26]}$

Hypoplastic inner ear

Agenesis of the inner ear canal

Altered cochlear morphology

Altered semicircular canal

Absence of the cochlear aqueduct

Absent/abnormally coursing facial nerve canal

Duplicated inner ear canal

Displaced endolymphatic duct

Conductive and sensorineural hearing deficitit ${ }^{3,15,16,23]}$

Temporal bone anomalies ${ }^{[15]}$

Poorly pneumatized mastoid antrum

Lengthened mastoid antrum

Enlarged cartilaginous portion of the eustachian tube lumen and absence of the cartilaginous lateral lamina of the eustachian tube

Cranial abnormalities ${ }^{[15,21]}$

$8-85$

Cranial asymmetry ${ }^{[15]}$

Microcephaly ${ }^{[15,16]}$

Skull defects ${ }^{[15]}$

Hypoplasia of petrous bone/ethmoid bone ${ }^{[15]}$

Neurological abnormalities ${ }^{[18,20,27]}$

Diffuse cerebral hypoplasia ${ }^{[27]}$

hydrocephalus ${ }^{[15,27]}$

Corpus callosum dysgenesis ${ }^{[27]}$

.

Mental retardation ${ }^{[3,15,20]}$

Intracranial dermoid/calcifications ${ }^{[15]}$

23-82

30

13

Encephalocele ${ }^{[15}$

Asymmetric lateral ventricles ${ }^{[15]}$

Hidrocephalus due to aqueduct of sylvius stenosis ${ }^{[24]}$

Corpus callosum lipoma ${ }^{[24]}$

Hypoplastic/absence of septum pellucidum ${ }^{[15]}$

Hypothalamic hamartoma ${ }^{[2]}$

Open myelomeningocele

Arnold-Chiari malformation

Frontal lobe dysplasia

Calcified anterior falx cerebri seizures

Cardiac abnormalities ${ }^{[2,9,17,18-20,24]}$

Conotruncal/outlet defects ${ }^{[2,19,24]}$

Fallot's tetralogy ${ }^{[15,24]}$ atresia $^{[24]}$

Transposition of great vessels ${ }^{[2]}$

Double inlet of the left ventricle

Septal defects ${ }^{[2,19,24]}$

Interatrial communication ostium secundum

Interventricular communication

Atrioventricular septal defect

Others

Patent ductus arterious ${ }^{[19]}$

Pulmonary artery stenosis ${ }^{[19]}$

Cor triatriatum ${ }^{[24]}$

Dextrocardia 
Table 1: Contd...

\begin{tabular}{|c|c|}
\hline Clinical features & Frequency $(\%)$ \\
\hline Skeletal abnormalities $^{[20]}$ & 23 \\
\hline Vertebral abnormalities $^{[4,14-16,24]}$ & $19-69$ \\
\hline \multicolumn{2}{|l|}{ Hemivertebrae ${ }^{[15,24]}$} \\
\hline \multicolumn{2}{|l|}{ Hypoplastic/butterfly vertebrae ${ }^{[15,24]}$} \\
\hline \multicolumn{2}{|l|}{ Absence/fusion of cervical vertebra } \\
\hline \multicolumn{2}{|l|}{ Kyphosis/scoliosis ${ }^{[15]}$} \\
\hline \multicolumn{2}{|l|}{ Lumbar lordosis/spina bifida occulta ${ }^{[24]}$} \\
\hline \multicolumn{2}{|l|}{ Rib alterations ${ }^{[24]}$} \\
\hline Radial abnormalities ${ }^{[15,24]}$ & 13 \\
\hline Short stature ${ }^{[15,16]}$ & $13-43$ \\
\hline Anomalies of extremities ${ }^{[15,16]}$ & $11-33$ \\
\hline \multicolumn{2}{|l|}{ Hormonal abnormalities ${ }^{[21]}$} \\
\hline \multicolumn{2}{|l|}{ Growth hormone deficiency ${ }^{[15,21]}$} \\
\hline Growth retardation $^{[15]}$ & 43 \\
\hline Esophagic/pulmonary abnormalities ${ }^{[9,15,24]}$ & 6.70 \\
\hline \multicolumn{2}{|l|}{ Pulmonary atresia ${ }^{[9]}$} \\
\hline \multicolumn{2}{|l|}{ Esophageal/duodenal atresia ${ }^{[24]}$} \\
\hline \multicolumn{2}{|l|}{ Tracheoesophageal fistula ${ }^{[24]}$} \\
\hline \multicolumn{2}{|l|}{ Laryngotracheomalacia $^{[24]}$} \\
\hline \multicolumn{2}{|l|}{ Bronchogenic cyst ${ }^{[24]}$} \\
\hline Abdominal abnormalities ${ }^{[20]}$ & 12 \\
\hline \multicolumn{2}{|l|}{ Pyloric hypertrophic stenosis } \\
\hline \multicolumn{2}{|l|}{ Accessory spleen } \\
\hline \multicolumn{2}{|l|}{ Umbilical hernia $^{[24]}$} \\
\hline Urogenital abnormalities ${ }^{[7,16,20]}$ & $18-23$ \\
\hline Renal anomalies-renal agenesis s $^{[7,15,16,22,24]}$ & $10-13$ \\
\hline \multicolumn{2}{|l|}{ Absent hymen } \\
\hline \multicolumn{2}{|l|}{ Renal hypoplasia/hydronephrosis } \\
\hline \multicolumn{2}{|l|}{ Genital alterations/short perineum } \\
\hline \multicolumn{2}{|l|}{ Maldescensus testis/hypospadias } \\
\hline Anal imperforations & \\
\hline
\end{tabular}

hypothesis). It is thought that the etiology may also be related to a deficiency in mesodermal formation or a defective interaction between the neural crest and mesoderm. ${ }^{[4]}$ Other evidence has suggested that there are genetic determinants in some cases. A few cases have been reported families with recessive autosomal or dominant, autosomal inheritance. ${ }^{[2]}$ The literature also contains several descriptions of chromosomal anomalies, environmental factors, drug ingestion (cocaine, retinoic acid, thalidomide and temoxifen), and maternal diabetes ${ }^{[2]}$ as factors that may contribute to the development of the disease. Jongbloet in his hypothesis states that among various complications of pregnancy, vaginal bleeding in very early pregnancy is closely related to the early condition of the fertilized egg and predates the formation of the relevant facial and vertebral structures in a 3-5 weeks old embryo. Therefore, this may be a common cause of dysmorphogenesis. ${ }^{[18]}$ In our case, the prenatal history revealed that the mother suffered repeated vaginal bleeding during the first trimester of her pregnancy, and this may be linked with the etiology in the current case.

Dentofacial anomalies may include cleft lip and palate, highly arched palate, hypoplasia of the maxillary and mandibular arches, micrognathia, gingival hypertrophy, supernumerary teeth, enamel and dentin malformations, and delayed tooth development. ${ }^{[4,9,15,16,20]}$ Due to the presence of an underdeveloped lower jaw, the patient may suffer malocclusion and macrostomia. Facial asymmetry and hypoplasia of the mandible are characteristic features of Goldenhar syndrome. The present patient showed marked malar and mandibular hypoplasia with bilateral cleft lip/plate and malalignment of the teeth.

Ophthalmologic anomalies occur in about $50 \%$ of cases and commonly involve epibulbar dermoids and lipodermoids followed by micropthalmia and upper palpebral coloboma. ${ }^{[16,20,24,25]}$ Limbal dermoids or lipodermoids are mainly located in the infratemporal region of the eye..$^{25]}$ Our patient presented with a limbal dermoid on the nasal region and a lipodermoid in the temporal region of the left eye, and an epibulbar dermoid in the right eye. In the right eye, the mass encroached the entire cornea with loss of vision.

Ear abnormalities vary, but as a rule, are required for the diagnosis of Goldenhar syndrome. ${ }^{[7]}$ Microtia and other minor ear malformations such as preauricular appendages and pits, either alone or in combination, are viewed as one of the minimal criteria for diagnosing this syndrome. ${ }^{[18,23,26,27]}$ Our patient had only minor ear abnormalities consisting of two preauricular tags, and this was a unilateral finding. He has not suffered any hearing disturbances or facial nerve dysfunction.

Vertebral anomalies reported in the literature include hypoplasia, and fusion or absence of certain vertebra, ${ }^{[14-16]}$ but no vertebral anomalies were detected in our patient. Despite the reported frequency of cardiovascular alterations ranging from $5 \%$ to $58 \%,,^{[17-20]}$ this patient had no cardiovascular alterations. Similarly, other systemic abnormalities including pulmonary, genitourinary, and/or gastrointestinal were not present in our patient.

Tasse et $a .^{[16]}$ reported that anomalies of the eye or orofacial clefts in Goldenhar syndrome patients are predictive of brain malformations. Consistent with this finding, our patient had ocular anomalies, an oral cleft, and also central nervous system alteration, specifically hydrocephalus.

Various classification systems have been introduced in order to clinically categorize the patient with Goldenhar syndrome or oculo-auriculo-vertebral spectrum and to aid in prognosis. ${ }^{[16,25]}$ The recently introduced classification system by Tasse et al. ${ }^{[16]}$ is simple and clinically applicable. In categorizing our patient in this classification system, the patient presented with 2 of their 3 minimal diagnostic criteria including unilateral preauricular appendages and hemifacial microsomia, classifying our patient as group $2 \mathrm{u}$. In addition our patient also presented with additional clinical features consisting of an orofacial cleft, dermoids, brain anomaly, delay of motor and speech development and short stature, attaining a score of 10/18, which reflects the severity of the syndrome.

The treatment of this disease varies with age and systemic associations. Although it may be mainly cosmetic in uncomplicated cases, it still demands a multidisciplinary 
team approach. ${ }^{[12]}$ There are several methods for surgical correction of facial hypoplasia, such as conventional reconstruction with bone grafts and distraction followed by future orthodontic treatment. ${ }^{[4]}$ Structural anomalies of the eyes and ears are corrected by reconstructive surgery. Furthermore, long-term regular follow-up is required to monitor the growth and development of patients.

De Catte et al. ${ }^{[29]}$ reported sonographic detection of Goldenhar syndrome in a foetus at 15 weeks gestation, by observing a maxillary cleft in association with unilateral micropthalmia, indicating of the possibility for early prenatal diagnosis, with the option for pregnancy termination in severe cases. Although these individuals typically have normal life span, the prognosis varies depending on the severity of the systemic associations.

Traditionally, the presence of ear abnormalities, which leads to the search of mandibular hypoplasia and vertebral alterations, is the main clinical feature associated with the diagnosis of Goldenhar syndrome. ${ }^{[25]}$ However, the absence of obvious characteristic features and the general lack of knowledge make the diagnosis difficult and delayed. Hence, this article represents an effort to summarize the characteristic features of patients with Goldenhar syndrome.

\section{ACKNOWLEDGMENTS}

We would like to acknowledge Dr. Sony K Jose, Ophthalmologist, Faculty of Medicine, AIMST University for her guidance in identifying the ocular features in the patient.

\section{REFERENCES}

I. Kokavec R. Goldenhar syndrome with various clinical manifestations. Cleft Palate Craniofac J 2006;43:628-34.

2. Gharehbaghi MM, Ghaemi MR. Goldenhar syndrome in an infant of diabetic mother. Iran J Pediatr 2010;20:131-4

3. Reddy MV, Reddy PP, Usha Rani P, Bindu LH. Facio-auricular vertebral syndrome-a case report. Indian J Hum Genet 2005; I : I 56-8.

4. Vinay C, Reddy RS, Uloopi KS, Madhuri V, Sekhar RC. Craniofacial features in Goldenhar syndrome. J Indian Soc Pedod Prev Dent 2009;27:1 2 I-4.

5. Gorlin RJ, Cohen MM, Levin LS. Syndromes of the Head and Neck. NewYork: Oxford University Press; 1990. p. 707-8.

6. Goldenhar M.Associations malformatives de l'oeil et l'oreille, en particulier le syndrome dermoide epibulbaire-appendices auriculaires-fistula auris congenital et ses relations avec la dysostose mandibulo-fistula auris congenita et ses relations avec la dysostose mandibulo-faciale.J Genet Hum 1952; 1:243-82. (in French)

7. Pinheiro AL, Araújo LC, Oliveira SB, Sampaio MC, Freitas AC. Goldenhar's syndrome - case report. Braz Dent / 2003; I4:67-70.

8. Gorlin RJ, Jue KL, Jacobsen U, Goldschmidt E. Oculoauriculo vertebral dysplasia. J Pediatr 1963;63:991-9.

9. Ghimire B, Thapa B, Shrestha U, Sayami P. Goldenhar syndrome with left bronchopulmonary agenesis: a rare association. J Inst Med 2010;32:60-2.

10. Smith DW. Facio-auriculovertebral spectrum. In: Jones KL, editor. Smith's Recognizable Patterns of Human Malformation. $4^{\text {th }}$ ed. Philadelphia: Saunders; 1988. p. 584-7.
II. Trivedi H, Murade S, Harne S, Aarbhave V. Incomplete presentation of Goldenhar syndrome. Bombay Hosp J 2007;49:519-2I.

12. Bielicka B, Necka A, Andrych M. Interdisciplinary treatment of patients with Goldenhar syndrome - Clinical reports. Dent Med Probl 2006;43:458-62.

13. Bayraktar S, Bayraktar ST, Ataoglu E, Ayaz A, Elevli M. Goldenhar's syndrome associated with multiple congenital abnormalities. J Trop Pediatr 2005;51:377-9.

14. Baum JL, Feingold M. Ocular aspects of Goldenhar's syndrome. Am J Ophthalmol 1973;75:250-7.

15. Wilson GN. Cranial defects in the Goldenhar syndrome. Am J Med Genet 1983; |4:435-43.

16. Tasse C, Böhringer S, Fischer S, Lüdecke HJ, Albrecht B, Horn D, Janecke A, Kling R, König R, Lorenz B. Oculo-auriculo-vertebral spectrum (OAVS): clinical evaluation and severity scoring of 53 patients and proposal for a new classification. Eur J Med Genet 2005;48:397-4I I.

17. Morrison PJ, Mulholland HC, Craig BG, Nevin NC. Cardiovascular abnormalities in the oculo-auriculo-vertebral spectrum (Goldenhar syndrome). Am J Med Genet 1992;44:425-8.

18. Strömland K, Miller M, Sjögreen L, Johansson M, Joelsson BM, Billstedt E, Gillberg C, Danielsson S, Jacobsson C, Andersson-Norinder J, Granstrom G. Oculo-auriculo-vertebral spectrum: associated anomalies, functional deficits and possible developmental risk factors. Am J Med Genet A 2007; I43A: 1317-25.

19. Digilio MC, Calzolari F, Capolino R, Toscano A, Sarkozy A, de Zorzi A, Dallapiccola B, Marino B. Congenital heart defects in patients with oculo-auriculo-vertebral spectrum (Goldenhar syndrome). Am J Med Genet A 2008; |46A: I8I5-9.

20. Touliatou V, Fryssira H, Mavrou A, Kanavakis E, Kitsiou-Tzeli S. Clinical manifestations in 17 Greek patients with Goldenhar syndrome. Genet Couns 2006; 17:359-70.

21. Yusufoglu AM, Cetinkaya E, Ceylaner S, Aycan Z, Kibar E, Ekici F, Kizilgun M. Goldenhar syndrome associated with growth hormone deficiency. Genet Couns 2008;19:173-6.

22. Ignacio Rodríguez J, Palacios J, Lapunzina P. Severe axial anomalies in the oculo-auriculo-vertebral (Goldenhar) complex. Am J Med Genet 1993;47:69-74.

23. Tuna EB, Orino D, Ogawa K, Yildirim M, Seymen F, Gencay K, Maeda T. Craniofacial and dental characteristics of Goldenhar syndrome: a report of two cases. J Oral Sci 201 I;53:121-4.

24. Rosa RF, Dall'agnol L, Zen PR, Pereira VL, Graziadio C, Paskulin GA. Oculo-auriculo-vertebral spectrum and cardiac malformations. Rev Assoc Med Bras 2010;56:62-6.

25. Martelli H Jr, Miranda RT, Fernandes CM, Bonan PR, Paranaíba LM, Graner E, Coletta RD. Goldenhar syndrome: clinical features with orofacial emphasis. J Appl Oral Sci 2010; 18:646-9.

26. Rosa RF, Silva AP, Goetze TB, Bier Bde A, Almeida ST, Paskulin GA, Zen PR. Ear abnormalities in patients with oculo-auriculo-vertebral spectrum (Goldenhar syndrome). Braz J Otorhinolaryngol 20I I;77:455-60.

27. Rosa RF, Graziadio C, Lenhardt R, Alves RP, Paskulin GA, Zen PR. Central nervous system abnormalities in patients with oculo-auriculo-vertebral spectrum (Goldenhar syndrome). Arq Neuropsiquiatr 2010;68:98-102.

28. Cohen J, Schanen NC. Branchial cleft anomaly, congenital heart disease, and biliary atresia: Goldenhar complex or Lambert syndrome? Genet Couns 2000;1 1:153-6.

29. De Catte L, Laubach M, Legein J, Goossens A. Early prenatal diagnosis of oculoauriculovertebral dysplasia or the Goldenhar syndrome. Ultrasound Obstet Gynecol 1996;8:422-4

How to cite this article: Kumaresan R, Srinivasan B, Narayanan M, Cugati N, Karthikeyan P. Craniofacial abnormalities in goldenhar syndrome: a case report with review of the literature. Plast Aesthet Res 2014;1:108-13.

Source of Support: Nil, Conflict of Interest: None declared.

Received: 27-02-2014; Accepted: 16-07-2014 